\title{
Observations on the rate of flow of digesta through the duodenum of sheep and on the recovery of polyethylene glycol and chromium sesquioxide from duodenal contents
}

\author{
A. Th. van 't Klooster, P. A. M. Rogers ${ }^{1}$ and H. R. Sharma 2 \\ Laboratory of Animal Physiology, Agricultural University, Wageningen, The Netheriands
}

Received 7 October, 1968

\begin{abstract}
Summary
The flow of digesta through the distal duodenum of Texel sheep was measured directly during 5 observation periods, 3 of 72 hours each and 2 of 120 hours each. At D.M. intakes of approximately $970 \mathrm{~g}$ per day the mean flow rate was $14-20 \mathrm{l}$ per day. Diurnal and between-day variations were appreciable. Flow rate tended to increase as the experiment progressed. In all experiments $\mathrm{PEG}$ and $\mathrm{Cr}_{2} \mathrm{O}_{3}$ were fed. The overall recoveries of these indicators from proportional samples of the total duodenal contents were $98 \%$ and $99 \%$ respectively. However, there was large variation between days and some variation between experiments. Direct measurement of the rate of flow of digesta agreed well with indirect measurement based on the concentration of the indicators in proportional samples of the total digesta.

A sampling technique involving the withdrawal of $7 \mathrm{ml}$ of digesta every 4 hours during a period of 120 hours yielded a bulk sample which, within analytical error, was representative of the soluble components of the total digesta. This 'random' sampling technique was less satisfactory for the insoluble components ( $D M$ and $\mathrm{Cr}_{2} \mathrm{O}_{3}$ ). It was suggested that withdrawal of larger samples at more frequent intervals could eliminate this problem.
\end{abstract}

\section{Introduction}

The rate of flow of digesta through the duodenum of sheep has been measured several times in recent years. Rate of flow is defined as the amount of material passing a given point in a given time. Measurement of the rate of flow has usually involved the use of duodenal re-entrant cannulae (Ash, 1961) which exteriorize the digesta. Total collection of the digesta from the proximal cannula is a simple procedure. After measuring, mixing and sampling, the digesta are returned to the intestine via the distal cannula (Hogan and Phillipson, 1960; Harris and Phillipson, 1962; Harrison and Hill, 1962; Bruce et al., 1967). Singleton (1961) measured the flow through the tubing connecting the two cannulae, with an electromagnetic flowmeter.

There are also studies on flow rate estimated by indirect methods using inert refer-

1 Present address: Agricultural Institute, Dunsinea, Castleknock, Dublin.

Present address: Animal Science Dept., University of Manitoba, Winnipeg, Canada. 
ence substances (Hogan, 1964) but these methods have not been tested or used to any large extent. Harris and Phillipson (1962) included chromium sesquioxide $\left(\mathrm{Cr}_{2} \mathrm{O}_{3}\right)$ in the rations of sheep fitted with duodenal re-entrant cannulae. These workers estimated the concentration of $\mathrm{Cr}_{2} \mathrm{O}_{3}$ in duodenal contents after total collections for 12 hour periods. The recovery of $\mathrm{Cr}_{2} \mathrm{O}_{3}$ from the duodenum in these experiments ranged from 87 to $93 \%$ of the dose given. With the same technique Bruce et al. (1967) got similar results. These workers found considerable variation in the recovery of $\mathrm{Cr}_{2} \mathrm{O}_{3}$ from duodenal digesta. Low recoveries, especially for polyethylene glycol (PEG), in faeces of ruminants have been seen several times (Corbett et al., 1958).

Phillipson (1952) and Hogan and Phillipson (1960) have discussed the errors which may arise when flow rates are measured by direct collection of digesta. Direct measurements of flow rate involve re-entrant cannulae. Animals with such cannulae require regular and frequent attention and the collection technique, while simple, is laborious and time consuming. Thus, measurement of flow rate using indirect methods would be preferable, if such methods were capable of yielding accurate results. Before indicators may be used to determine the amount of digesta flowing through the duodenum, it would be desirable to determine the nature and extent of the diurnal variations in the concentration and flow rate of these components.

The work described in this paper was designed to obtain information on the recovery and on the pattern of passage of a soluble (polyethylene glycol-PEG) and an insoluble $\left(\mathrm{Cr}_{2} \mathrm{O}_{3}\right)$ indicator in the duodenum of sheep with a view to evolving a reliable 'random' sampling technique i.e. the daily collection of a relatively small proportion of the duodenal contents, which on analysis would provide an accurate value for the quantities of any particular nutrient that passed through the duodenum per day.

\section{Experimental}

\section{Animals}

Two Texel sheep, Hans (a wether) and Grietje (a hogget) were used. They weighed about 50 and $45 \mathrm{~kg}$ respectively. Moulded hard plastic re-entrant cannulae were inserted into the distal part of the duodenum of both sheep, using an operation technique similar of that of Hogan and Phillipson (1960). Surgery was performed at six and three months before the start of the experiments. Both animals were in good health.

\section{Rations and experimental periods}

In experiments 1 and 2 the ration consisted of $700 \mathrm{~g}$ straw pellets and $390 \mathrm{~g}$ of a concentrate mixture which contained $100 \mathrm{~g}$ maizemeal, $100 \mathrm{~g}$ starch, $150 \mathrm{~g}$ cellulose powder, $5 \mathrm{~g}$ mineral mixture, $3 \mathrm{~g}$ vitamin mixture and urea in amounts of $40 \mathrm{~g}$ (Hans, expt 1), $30 \mathrm{~g}$ (Hans, expt 2) and $20 \mathrm{~g}$ (Grietje, expt 2). In experiment 3 the ration consisted of $1000 \mathrm{~g}$ hay and about $120 \mathrm{~g}$ maizemeal. In this experiment Grietje refused approximately $60 \mathrm{~g}$ of the stemmier parts of the hay. This amount must be subtracted from the ration. PEG $(10 \mathrm{~g})$ and $\mathrm{Cr}_{2} \mathrm{O}_{3}(2 \mathrm{~g}$ in expt $1,1.94 \mathrm{~g}$ in expt 2 and 3$)$ were mixed with the concentrates. The rations were fed in equal parts morning and evening. The indicators were given for six days before each collection period, and were given until the end of the period. Collection periods lasted for 72 hours (expt 1 and 2) or 120 hours (expt 3). Care was taken to ensure that all the indicators were ingested. Water was available ad lib. 
Direct measurement of the rate of flow of digesta through the duodenum

All the digesta which flowed out of the proximal cannula were collected and measured as described earlier (Sharma et al., 1969). After each sampling, the remaining part of the collected digesta was heated to approximately $40^{\circ} \mathrm{C}$ and returned to the sheep. At the end of each hour the volumes of all the individual collections for that hour were totalled and noted.

\section{Sampling}

In all 3 experiments, the digesta were sampled proportionally, (i.e.) $7 \%$ of each collection was transferred to the sample bottle allocated for that hour. In addition, in experiment 3 , we compared the results obtained by proportional sampling of the total contents with the results obtained from 'random' samples. In this experiment, $7 \mathrm{ml}$ samples were withdrawn from whatever digesta were present in the collection bottle at 30 minutes over the hour. The 'random' samples were taken every 4 hours. The samples were stored in one of four bottles A, B, C or D. Each of these bottles contained 30 subsamples of $7 \mathrm{ml}$ each. Thus bottle A contained the bulked samples taken at $1 / 2,41 / 2,81 / 2$, etc. hours after the start of the experiment, and bottle $\mathrm{D}$ contained the samples taken at $31 / 2,71 / 2,11 \frac{1}{2}$, etc. hours.

\section{Recovery of the indicators}

The recovery of $\mathrm{Cr}_{2} \mathrm{O}_{3}$ was calculated as the product of the measured flow rate of digesta $\times$ conc. of $\mathrm{Cr}_{2} \mathrm{O}_{3}$ in the digesta. The recovery of $\mathrm{PEG}$ was calculated as the product of the flow rate of digesta $\times$ conc. of PEG $\times(100-D M \%$ of digesta $) / 100$. (It will be shown later that the correction factor $(100-D M \%) / 100$ is necessary because all the PEG is present in the fluid phase of the digesta only). The \% recovery of the indicators was calculated as the amount of indicator recovered per day $\times 100$ and divided by the dose of indicator per day.

\section{Analytical procedures}

PEG was estimated in the supernatent of centrifuged duodenal contents following the method of Hydén (1955). The turbidity was read after exactly 10 minutes after the addition of trichloro-acetic acid.

The recovery of PEG in duodenal contents, using this method was checked in the following way. PEG-free duodenal contents were collected from the two sheep. Two subsamples of each sample were put into weighed volumetric cylinders. The weight and volume of the subsamples were recorded. One $\mathrm{ml}$ of PEG soln. containing $10 \mathrm{~g}$ PEG per $100 \mathrm{ml}$ was added to each cylinder. After thorough mixing the duodenal contents were centrifuged at $2400 \mathrm{~g}$ for approximately 25 minutes. PEG concentration was estimated in duplo in $2 \mathrm{ml}$ aliquots of all supernatants. The weight of water in the sample was calculated from the formula sample weight multiplied by $(100-$ $\mathrm{DM} \%) / 100$. To this was added the weight of $1 \mathrm{ml}$ of PEG solution. The amount of PEG in the fluid part was then calculated from the concentration multiplied by the weight of water. Table 1 shows that this amount was identical with the dose given. Thus all the PEG appears to be dissolved in the fluid phase, hence the correction for dry matter percentage when calculating the recovery of PEG (see above).

$\mathrm{Cr}_{2} \mathrm{O}_{3}$ was determined by ashing about $1 \mathrm{~g}$ of the dried material and digesting the ash with $3 \mathrm{ml} 10 \% \quad \mathrm{MnSO}_{4}$ in $80 \%$ phosphoric acid and $4 \mathrm{ml}$ potassium bromate solution $(4.5 \%)$ until the mixture turned dark purple. The digestion flask was allowed 
DUODENAL FLOW RATE IN SHEEP AND RECOVERY OF PEG AND $\mathrm{Cr}_{2} \mathrm{O}_{3}$

Table 1 The \% recovery of a known dose of PEG from the fluid phase of duodenal contents

\begin{tabular}{|c|c|c|c|c|c|c|c|c|c|}
\hline Sample & & $\begin{array}{l}\text { Volume of } \\
\text { sample } \\
(\mathrm{ml})\end{array}$ & $\begin{array}{l}\text { Weight of } \\
\text { sample } \\
\text { (g) }\end{array}$ & $\begin{array}{c}\text { Dry } \\
\text { matter } \\
\%\end{array}$ & $\begin{array}{c}\text { PEG conc. } \\
\text { in fluid } \\
(g / l)\end{array}$ & $\begin{array}{c}\text { Weight }{ }^{1} \text { of water } \\
\text { in sample } \\
(\mathrm{g})\end{array}$ & $\begin{array}{c}\text { PEG recovered } \\
\text { from fluid } \\
\text { phase }(g)\end{array}$ & $\begin{array}{c}\text { Dose } \\
\text { of } \\
P E G(g)\end{array}$ & $\begin{array}{c}\% \text { recovery of } \\
\text { PEG from } \\
\text { fluid phase }\end{array}$ \\
\hline \multirow[t]{2}{*}{ Grietje } & 1 & 100.5 & 101.1 & 6.44 & 1.045 & 95.59 & .100 & .100 & 100 \\
\hline & 2 & 93.0 & 92.9 & & 1.139 & 87.92 & .100 & .100 & 100 \\
\hline \multirow[t]{2}{*}{ Hans } & 1 & 99.5 & 100.2 & 4.64 & 1.036 & 96.55 & .100 & .100 & 100 \\
\hline & 2 & 103.0 & 103.3 & & 1.014 & 99.51 & .101 & .100 & 101 \\
\hline
\end{tabular}

1 sample weight $\times(100-\mathrm{DM} \%) / 100+1 \mathrm{~g}$ PEG-solution

to cool. The contents were then transferred quantitatively into a $200 \mathrm{ml}$ volumetric flask with distilled water. $25 \mathrm{ml}$ calciumchloridesoln. $\left(\mathrm{CaCl}_{2}-6 \mathrm{H}_{2} \mathrm{O}, 14.8 \%\right)$ were then added and the volume made up to $200 \mathrm{ml}$. This was further diluted to give approximately $3 \mathrm{mg} \mathrm{Cr}$ per liter. The diluted samples were immediately read in the atomic absorption flame spectrophotometer (Techtron A 100) at a wavelength of $357.8 \mathrm{~m} \mu$ against a Cr-standard of $3 \mathrm{mg}$ per 1 which was processed in the same way as the samples.

Dry matter $\%$ of the digesta was estimated as follows: about $30 \mathrm{~g}$ of fresh duodenal contents were weighed in platinum crucibles and dried overnight at $105^{\circ} \mathrm{C}$ and reweighed. The dry matter was ashed afterwards at $500^{\circ} \mathrm{C}$ and the ash acidified with 1 to $2 \mathrm{ml}$ of conc. $\mathrm{HCl}$ on a water bath and made up to $100 \mathrm{ml}$. After proper dilution sodium and potassium were estimated using a flamephotometer (KIPP HD 45). Calcium and magnesium were estimated using an atomic absorption flame spectrophotometer (Techtron A 100). Phosphorous was estimated colorimetrically (Scheel, 1936).

\section{Experiments}

In the first experiment the duodenal contents of one animal (Hans) were collected during 72 continuous hours. The dry matter intake was $980 \mathrm{~g}$ per day. In this preliminary experiment all the proportional samples were pooled and the pooled samples analysed for $\mathrm{Cr}_{2} \mathrm{O}_{3}, \mathrm{PEG}$ and $\mathrm{DM} \%$.

In experiment 2 two sheep were used. The ration was similar for both animals except for a minor difference in urea content. Dry matter intake was about $970 \mathrm{~g}$ per day and the animals were fed at 12 hour intervals, at 7 a.m. and 7 p.m. Collections were made for 72 continuous hours. There were 72 proportional samples from each sheep, each sample corresponding to each hour of the 72 hour period. All samples were analysed separately for $\mathrm{PEG}, \mathrm{Cr}_{2} \mathrm{O}_{3}$ and the DM \%.

In experiment 3 the same two sheep were used as in experiment 2. The rations were changed to hay $(1000 \mathrm{~g})$ and concentrates $(120 \mathrm{~g})$ with a total dry matter intake of about $960 \mathrm{~g}$ per day. The feeding times were at $7.30 \mathrm{a} . \mathrm{m}$. and $5.15 \mathrm{p} . \mathrm{m}$. The collection period lasted for 120 continuous hours. During this 5 day period the samples of the first hour of each day were bulked together. The same was done for the second, third etc., hours of each day. Thus for each sheep there were 24 samples, sample 1 corresponding to the bulked samples for the first hour of each of the 5 days, sample 24 corresponding to the bulked samples of the 24th hour of each of the 5 days etc. In the rest of this paper these samples are called the proportional samples. 
In this experiment the composition of the $(7 \%)$ proportional samples of the total duodenal digesta was compared with the composition of 'random' samples taken at 4-hour intervals. The concentrations of $\mathrm{PEG}, \mathrm{Cr}_{2} \mathrm{O}_{3}$ and dry matter were determined as in experiment 2. Moreover, the concentrations of $\mathrm{K}, \mathrm{Na}, \mathrm{Ca}, \mathrm{Mg}$ and $\mathrm{P}$ were determined in all samples.

\section{Results and discussion}

The results of the main flow rate, concentration of $\mathrm{PEG}, \mathrm{Cr}_{2} \mathrm{O}_{3}$ and recovery of indicators are given in Table 2. In expt 1 the mean flow rate increased from $633 \pm$ $97 \mathrm{ml}$ per $\mathrm{h}$ on day 1 to $898 \pm 113 \mathrm{ml}$ per $\mathrm{h}$ on day 3 . The flow on day 2 was intermediate.

Since no information was obtained in this experiment on the variation in the PEG and $\mathrm{Cr}_{2} \mathrm{O}_{3}$ concentrations and on the pattern of flow during the day, special attention was paid to these points in experiment 2 and 3 (Table 2 and Fig. 1 and 2).

Table 2 The mean' flow rate $(\mathrm{ml} / \mathrm{h})$ by direct measurement, the mean ${ }^{1}$ concentration of PEG, $\mathrm{Cr}_{3} \mathrm{O}_{3}$ and $\mathrm{DM}$, the standard deviations of the means ${ }^{1}$, and the \% recovery of the indicators from the duodenal digesta

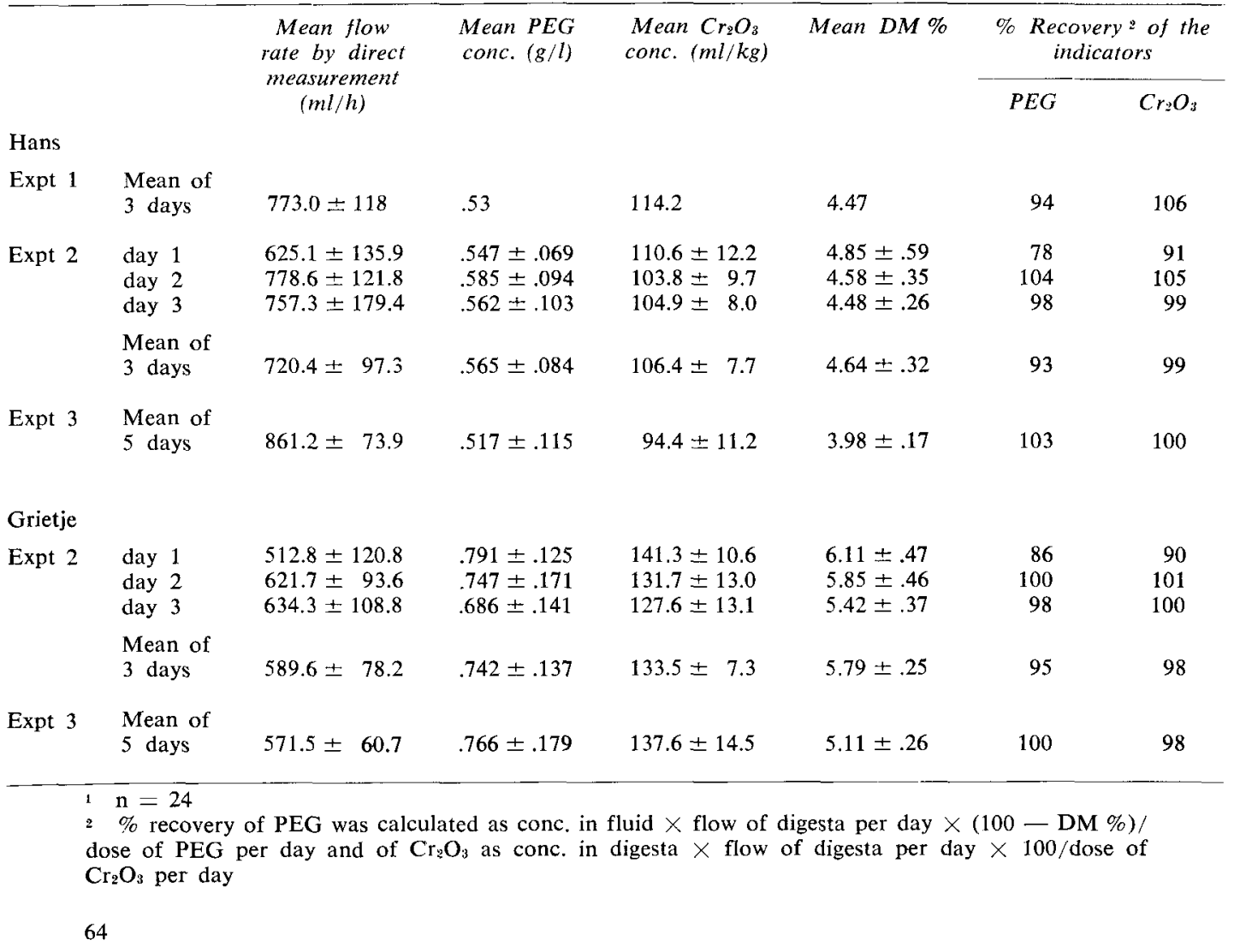



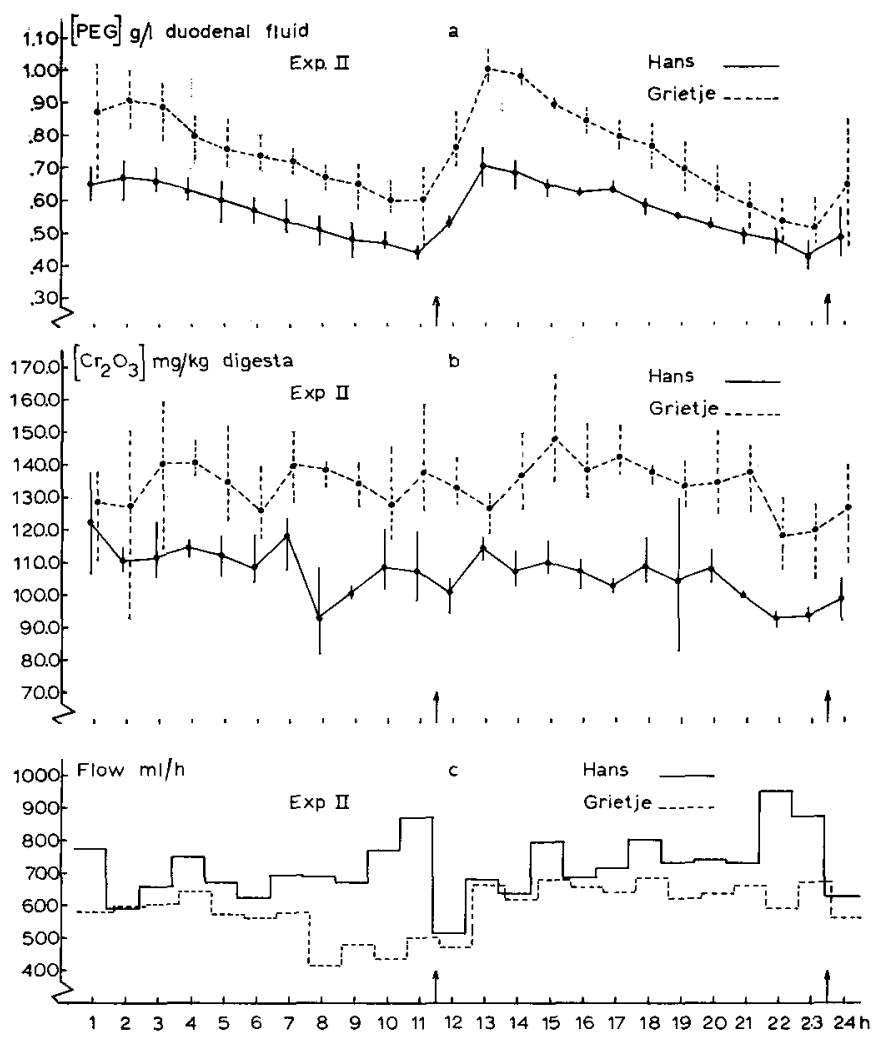

Fig. 1 The concentrations - mean of three days - of $\mathrm{PEG}$ and $\mathrm{Cr}_{2} \mathrm{O}_{3}$ in the hourly samples and the flow rate in $m l$ per hour in experiment 2. The ranges are shown by the vertical lines. The arrows point to the times of feeding

In experiment 2 and 3 , as in expt 1 , the flow of digesta was lowest on the first day. In experiment 2 there was no further increase after the second day (Table 2) but in experiment 3 with Hans the flow rate increased from day 1 to day 5. Flow rates for Hans were 670, 806, 911, 956 and $963 \mathrm{ml}$ per hour and for Grietje 482, 566, 602,621 and $505 \mathrm{ml}$ per hour. During the first 12 hours of collection periods, Harris and Phillipson (1962) also collected smaller quantities of duodenal contents from sheep which were not accustomed to the procedures used during routine collections. Our animals received no pre-collection training, which may explain the low flow rate on the first day. That the flow rate was abnormally low on the first day is suggested by the low recoveries of that day compared with the other days. The further, but small increase in flow rate from the first day onwards may be an effect of the collection procedures (Harris and Phillipson, 1962).

The standard deviations (SD) of the means, given in Table 2, are considerable. When the flow rate for each corresponding hour $(n=24)$ was averaged in the 3 days of expt 2 and the 5 days of expt 3, the SD was about $10 \%$ of the mean. However, if we calculated the SD of the mean, based on 72 separate hours in experiment 2 and 

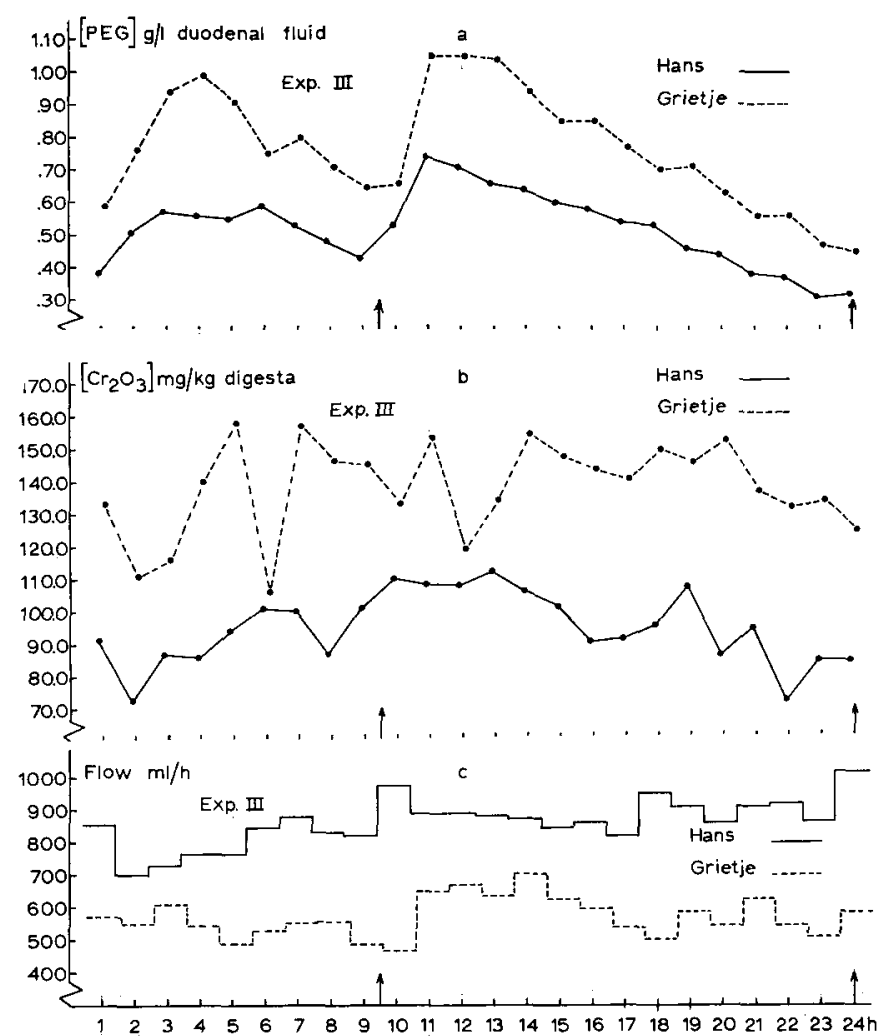

Fig. 2 The concentrations - mean of five days - of $\mathrm{PEG}$ and $\mathrm{Cr}_{2} \mathrm{O}_{3}$ in the hourly samples and the flow rate in $\mathrm{ml}$ per hour in experiment 3. The arrows point to the times of feeding

on 120 hours in experiment 3, instead of 24 (each value being the mean of 3 and 5 days resp., the S.D.-s are higher viz. \pm 161 and $\pm 126 \mathrm{ml}$ for Hans and \pm 120 and \pm 118 for Grietje in experiment 2 and 3 respectively.

The flow rate through the duodenum of Hans was higher on all days than the flow rate of Grietje. In experiment 2 the mean flow rate of digesta through the duodenum of Hans was lower than in experiment 3, viz. $720 \mathrm{ml}$ and $861 \mathrm{ml}$ per hour. This may be caused by the change of ration. However, there was not such an effect in Grietje. As this animal refused in experiment 3 per day about $60 \mathrm{~g}$ of the more stemmier parts of the hay, the lower DM intake may have counteracted a ration effect. The quantities of duodenal contents collected in the 1 st, $2 \mathrm{nd}, 3 \mathrm{rd}, \ldots, 24$ th hour for each of the three days (experiment 2) and five days (experiment 3 ) are averaged and the averaged vaules are given in Fig. $1 \mathrm{c}$ and 2c. For Hans the highest flow rate was found before and during feeding. For Grietje, however, the flow was fairly small at that time. The flow tended to increase in the 'night' hours. The differences between the mean flow per $\mathrm{h}$ in the periods from 8 p.m. to 8 a.m. and 8 a.m. to 8 p.m. were $59 \mathrm{ml}$ and $105 \mathrm{ml}$ in experiment 2 and 66 and $27 \mathrm{ml}$ in experiment 3 for Hans and Grietje respectively. 
The flow of digesta from the abomasum of the sheep has been discussed by Phillipson and Ash (1965). Our observations on the diurnal pattern of flow and the influence of feeding and ruminating on the flow rate agree basically with those described by these authors. However, the volume of material passing daily to the duodenum in our experiments was of the order of 14 to 201 . This is much higher than the 8.5-11.0 1 per day mentioned by Phillipson and Ash for Scottisch Blackface sheep and 10 to 121 per day for Clun Forest sheep. Their animals ingested $700-1000 \mathrm{~g}$ of food daily in two feeds. Flow rates of the same order as we measured, were found by Hogan (1964) in experiments with English Leicester $\times$ Merino crossbred sheep on ad lib intakes. The high flow rate through the duodenum of our sheep can partly be explained by the fact that the proximal cannula of the re-entrant cannulae was placed about $15 \mathrm{~cm}$ distal to the entrance of the common bile duct. Measurement of the flow of the digesta from this cannula was therefore an index of the flow along the distal part of the duodenum and differed from abomasal contents since bile, pancreatic juice and duodenal secretion had been added to the digesta.

From the work of Harrison and Hill (1962) on the secretion rates of duodenal juice, bile and pancreatic juice, it can be deduced that the amounts of these secretions are rather small and could not fully account for the large differences in duodenal flow rate in our sheep compared with those of Phillipson and Ash. Other factors such as differences in ration composition as well as differences between animals and between breeds probably play an important role in determining the flow rate through the duodenum.

The mean quantities of dry matter that passed through the duodenum each day were about equal for both animals in experiment 2 viz. 802 and $818 \mathrm{~g}$ in Hans and Grietje respectively. In experiment 3 , the DM flow per day was about $825 \mathrm{~g}$ for Hans and $701 \mathrm{~g}$ for Grietje. A substantial part of duodenal digesta DM is endogenous, i.e. arises from saliva, abomasal fluid and other secretory products. The lower daily passage of $\mathrm{DM}$ in Grietje in experiment 3 was due to the refusal of $60 \mathrm{~g}$ hay per day - the stemmier parts were not eaten - and also due to a lower amount of secretory fluids Grietje secreted about 81 less fluid per day than Hans in experiment 3.

The mean concentrations of $\mathrm{PEG}$ and $\mathrm{Cr}_{2} \mathrm{O}_{3}$ from hour to hour are shown in Figs. $1 \mathrm{a}$, b and $2 a, b$. These Figures show the difference in behaviour of the soluble (PEG) and the insoluble $\left(\mathrm{Cr}_{2} \mathrm{O}_{3}\right)$ indicator. The PEG concentration reached a maximum shortly after feeding (except in experiment 3, when the rise in concentration was more gradual) and decreased regularly afterwards. $\mathrm{C}_{2} \mathrm{O}_{3}$ concentration did not show such a constant pattern during the day. The time interval between the start of the increase in PEG concentration and feeding times was remarkably short, within one hour in these experiments.

The \% recovery of $\mathrm{PEG}$ and $\mathrm{Cr}_{2} \mathrm{O}_{3}$ is shown in Table 2. The overall mean \% recovery of the indicators during the 5 observation periods (expt 1,2 and 3 together) was $98 \%$ for $\mathrm{PEG}$ and $99 \%$ for $\mathrm{Cr}_{2} \mathrm{O}_{3}$. The range for the mean $\%$ recovery for the 5 periods was $93-103 \%$ for $\mathrm{PEG}$, and $95-106 \%$ for $\mathrm{Cr}_{2} \mathrm{O}_{3}$. However, the range for the $\%$ recovery of indicator was wider when the recovery for individual days was examined (expt 2) - viz. 78-104\% for PEG and 86-101\% for $\mathrm{Cr}_{2} \mathrm{O}_{3}$. The high recoveries of $\mathrm{PEG}$ and $\mathrm{Cr}_{2} \mathrm{O}_{3}$ in the present experiments show that both indicators are suitably for measuring the amount of digesta flowing through the duodenum per day (Sperber et al., 1953) provided that the preliminary and experimental periods are suitable long. However, apart from proportional sampling after total collection, reliable methods of sampling the digesta passing a given point in the small intestine of rumi- 
nants are lacking at present. Total collection of duodenal contents is not possible in animals with $T$-piece cannulae, unless the distal segment of the intestine is blocked by some sort of ballon etc. which may cause an abnormal response in flow rate or secretion rate. Hence we tested a 'random' sampling technique in experiment 3 . In successive 4-hour periods a sample was taken from whatever duodenal contents were present in the collecting bottles at 30 minutes over the hour (A, B, C and D samples) as described under experimental.

The mean concentrations of $\mathrm{PEG}, \mathrm{Cr}_{2} \mathrm{O}_{3}, \mathrm{DM}$ and minerals of the 24 proportional ${ }^{3}$ saniples of each sheep and the mean concentrations in the 'random' samples A, B, C and $\mathrm{D}$ are given in Table 3 (experiment 3 ).

The 'random' samples (A, B, C and D) were each composed of 30 samples of $7 \mathrm{ml}$ each. If the concentrations of $\mathrm{PEG}, \mathrm{K}, \mathrm{Ca}, \mathrm{Mg}$ and $\mathbf{P}$ in the 'random' samples and the mean of the 24 proportional samples are compared, it is seen that the differences between the means are small. The differences can be attributed largely to analytical error. The concentrations of $\mathrm{Na}$ in the 'random' samples, however, differ in three cases from the mean of the 24 proportional samples. This was unexpected, as the concentration of $\mathrm{Na}$ in duodenal contents of ruminants is fairly constant for any particular ration. Therefore it should not make much difference if the samples were taken proportionally or at random. There is some reason to attribute the discrepancy to analytical error as the flame photometer yielded less accurate results for sodium than for potassium.

Table 3 The mean concentration of $P E G, C r, O$, $D M$ and minerals in the 24 proportional samples and in the four 'random' samples

\begin{tabular}{|c|c|c|c|c|c|c|}
\hline & \multirow{2}{*}{$\begin{array}{c}\text { Mean of } \\
\text { the } 24 \\
\text { samples }\end{array}$} & \multirow{2}{*}{$\begin{array}{l}\text { S.D. of } \\
\text { the } \\
\text { mean }\end{array}$} & \multicolumn{4}{|c|}{$\begin{array}{c}\text { Concentration in 'random' samples } \\
\text { taken every } 4 \text { hours }\end{array}$} \\
\hline & & & $A$ & $B$ & $C$ & $D$ \\
\hline \multicolumn{7}{|l|}{ Hans } \\
\hline $\begin{array}{l}\mathrm{PEG}(\mathrm{g} / \mathrm{l}) \\
\mathrm{Cr}_{2} \mathrm{O}_{3}(\mathrm{mg} / \mathrm{kg}) \\
\mathrm{DM}(\%) \\
\mathrm{K}(\mathrm{meq} / \mathrm{kg}) \\
\mathrm{Na} \quad, \\
\mathrm{Ca} \quad, \\
\mathrm{Mg} \quad, \\
\mathrm{P}(\mathrm{mmol} / \mathrm{kg})\end{array}$ & $\begin{array}{c}.517 \\
94.4 \\
3.98 \\
25.67 \\
79.26 \\
10.95 \\
5.91 \\
14.69\end{array}$ & $\begin{array}{c}.115 \\
11.2 \\
.17 \\
1.65 \\
4.13 \\
.61 \\
.52 \\
.66\end{array}$ & $\begin{array}{c}.510 \\
95.6 \\
3.92 \\
25.12 \\
83.68 \\
11.23 \\
5.72 \\
14.15\end{array}$ & $\begin{array}{c}.509 \\
92.8 \\
4.13 \\
25.26 \\
82.93 \\
10.77 \\
5.96 \\
14.09\end{array}$ & $\begin{array}{c}.520 \\
91.5 \\
4.12 \\
25.44 \\
85.23 \\
10.60 \\
5.72 \\
14.42\end{array}$ & $\begin{array}{c}.523 \\
93.0 \\
3.93 \\
25.34 \\
78.80 \\
10.85 \\
5.90 \\
14.59\end{array}$ \\
\hline \multicolumn{7}{|l|}{ Grietje } \\
\hline $\begin{array}{l}\mathrm{PEG}(\mathrm{g} / \mathrm{l}) \\
\mathrm{Cr}_{2} \mathrm{O}_{3}(\mathrm{mg} / \mathrm{kg}) \\
\mathrm{DM}(\%) \\
\mathrm{K}(\mathrm{meq} / \mathrm{kg}) \\
\mathrm{Na} \quad, \\
\mathrm{Ca} \quad, \\
\mathrm{Mg} \quad, \\
\mathrm{P}(\mathrm{mmol} / \mathrm{kg})\end{array}$ & $\begin{array}{c}.766 \\
137.6 \\
5.12 \\
28.86 \\
75.91 \\
14.86 \\
7.82 \\
19.39\end{array}$ & $\begin{array}{c}.179 \\
14.5 \\
.26 \\
3.11 \\
5.08 \\
.61 \\
1.00 \\
.76\end{array}$ & $\begin{array}{c}.776 \\
132.5 \\
5.01 \\
28.46 \\
80.24 \\
14.91 \\
7.87 \\
20.16\end{array}$ & $\begin{array}{c}.770 \\
126.2 \\
4.97 \\
28.21 \\
79.15 \\
14.70 \\
7.68 \\
18.81\end{array}$ & $\begin{array}{c}.807 \\
126.2 \\
5.34 \\
29.18 \\
75.28 \\
14.56 \\
7.66 \\
20.41\end{array}$ & $\begin{array}{c}.769 \\
131.4 \\
4.79 \\
28.44 \\
77.39 \\
15.12 \\
7.81 \\
18.35\end{array}$ \\
\hline
\end{tabular}

3 Each of the 24 samples was composed of aliquots from each corresponding hour of each of the 5 days. Each aliquot was $7 \%$ of the total digesta passing in each particular hour. 
Analytical error alone, however, could not account for the larger discrepancies in the concentrations of $\mathrm{Cr}_{2} \mathrm{O}_{3}$ and $\mathrm{DM}$ between the 'random' samples and the proportional sample mean. It would be relevant to estimate the sampling error, especially in the case of $\mathrm{Cr}_{2} \mathrm{O}_{3}$ and DM. It is not possible to estimate this error directly from our data. However, ' $\mathrm{t}$ ' tests on the differences in composition $\left(\mathrm{PEG}, \mathrm{Cr}_{2} \mathrm{O}_{3}, \mathrm{DM}, \mathrm{K}, \mathrm{Na}\right.$, $\mathrm{Ca}, \mathrm{Mg}, \mathrm{P}$ ) between samples $\mathrm{A}, \mathrm{B}, \mathrm{C}$ and $\mathrm{D}$ and the mean composition of the digesta sampled (proportionally) during the hours corresponding to those in which samples $\mathrm{A}$, $\mathbf{B}, \mathbf{C}$ and $\mathbf{D}$ were collected, gave ' $t$ ' values which generally failed to reach significance at the $5 \%$ level. Only 8 out of 64 of the calculated differences were $>5 \%$ of the mean values, and all were $<10 \%$ of the mean. Thus it was concluded that the 'random' samples at 4 hours intervals are acceptable substitutes for the mean of the 6 proportional samples which were collected during times corresponding to the 'random' collections. However, in certain investigations the accuracy of such a random sampling technique may be sometimes less than one might desire, particularly for insoluble material ( $\left.\mathrm{DM}, \mathrm{Cr}_{2} \mathrm{O}_{3}\right)$. Withdrawal of larger samples at more frequent intervals might yield a more representative bulk sample. In this context, an automatic sampling device which could withdraw such samples at 1 or 2 hour intervals, would appear to be very useful in alimentary studies. The technical difficulties of designing such a device would be considerable, however, in view of the physical characteristics of duodenal contents.

We calculated the correlations between the concentration of PEG and the substances under investigation as well as between the concentrations of $\mathrm{Cr}_{2} \mathrm{O}_{3}$ and these substances, in the samples for each of the 24 hours of the day. The correlation-coefficients, given in Table 4, were low in many instances and varied considerably. It is generally accepted that an insoluble marker indicates the movement of the solid phases of the digesta more accurately than the liquid phases. The fact that the mean correlation-coefficient between the contents of $\mathrm{Cr}_{2} \mathrm{O}_{3}$ and $\mathrm{DM}$ was higher than the mean correlation-coefficient between the concentrations of PEG and DM did support this concept. However, the highly variable correlation-coefficients between $\mathrm{Cr}_{2} \mathrm{O}_{3}$ and DM in experiment 2 and 3 show the danger of generalization of such a concept.

Table 4 Correlation-coefficients between the concentration of the indicators and the dry matter + mineral content of duodenal digesta

\begin{tabular}{|c|c|c|c|c|c|c|c|c|}
\hline & & $\begin{array}{l}P E G \\
\mathrm{Cr}_{2} \mathrm{O}_{3}\end{array}$ & $\begin{array}{c}P E G \\
D M\end{array}$ & $\begin{array}{c}P E G \\
K\end{array}$ & $\begin{array}{c}P E G \\
\mathrm{Na}\end{array}$ & $\begin{array}{c}P E G \\
C a\end{array}$ & $\begin{array}{c}P E G \\
M g\end{array}$ & $\begin{array}{c}P E G \\
P\end{array}$ \\
\hline Expt 2 & $\begin{array}{l}\text { Hans } \\
\text { Grietje }\end{array}$ & $\begin{array}{l}0.65 \\
0.35\end{array}$ & $\begin{array}{l}0.53 \\
0.02\end{array}$ & & & & & \\
\hline Expt 3 & $\begin{array}{l}\text { Hans } \\
\text { Grietje }\end{array}$ & $\begin{array}{l}0.60 \\
0.11\end{array}$ & $\begin{array}{l}0.16 \\
0.58\end{array}$ & $\begin{array}{l}0.88 \\
0.93\end{array}$ & $\begin{array}{l}0.10 \\
0.16\end{array}$ & $\begin{array}{l}0.14 \\
0.45\end{array}$ & $\begin{array}{l}0.55 \\
0.87\end{array}$ & $\begin{array}{l}0.36 \\
0.41\end{array}$ \\
\hline & & & $\begin{array}{c}\mathrm{Cr}_{2} \mathrm{O}_{3} \\
\mathrm{DM}\end{array}$ & $\begin{array}{c}\mathrm{Cr}_{2} \mathrm{O}_{3} \\
K\end{array}$ & $\begin{array}{c}\mathrm{Cr}_{2} \mathrm{O}_{3} \\
\mathrm{Na}\end{array}$ & $\begin{array}{c}\mathrm{Cr}_{2} \mathrm{O}_{3} \\
\mathrm{Ca}\end{array}$ & $\begin{array}{c}\mathrm{Cr}_{2} \mathrm{O}_{3} \\
\mathrm{Mg}\end{array}$ & $\begin{array}{c}\mathrm{Cr}_{2} \mathrm{O}_{3} \\
P\end{array}$ \\
\hline Expt 2 & $\begin{array}{l}\text { Hans } \\
\text { Grietje }\end{array}$ & & $\begin{array}{l}0.78 \\
0.62\end{array}$ & & & & & \\
\hline Expt 3 & $\begin{array}{l}\text { Hans } \\
\text { Grietje }\end{array}$ & & $\begin{array}{l}0.08 \\
0.44\end{array}$ & $\begin{array}{l}0.47 \\
0.15\end{array}$ & $\begin{array}{l}0.09 \\
0.15\end{array}$ & $\begin{array}{l}0.22 \\
0.34\end{array}$ & $\begin{array}{l}0.28 \\
0.11\end{array}$ & $\begin{array}{l}0.02 \\
0.48\end{array}$ \\
\hline
\end{tabular}




\section{Conclusions}

The overall recovery of $\mathrm{PEG}$ and $\mathrm{Cr}_{2} \mathrm{O}_{3}$ was almost $100 \%$. This shows that these indicators can be used to measure the duodenal flow rate directly. To obtain accurate results, however, a representative sample of the total digesta is essential. This entails frequent sampling over a sufficiently long collection period. This is due to the diurnal and between-day variation in the indicator concentrations and also due to the differences in the pattern of passage of $P E G, C_{2} \mathrm{O}_{3}, D M$ and other components. The low and variable correlations between the concentrations of the indicators and of several components of the digesta also suggest the necessity of frequent sampling.

A 'random' sampling technique can be used with reasonable accuracy to avoid the labour and time involved in total collections and proportional sampling. Re-entrant cannulae may then be replaced by the simpler and more-easily managed $T$-piece cannulae.

\section{Acknowledgement}

We would like to thank the director of the laboratory, prof. A. M. Frens, for his encouragement and for his co-operation in the surgery, dr. ir. A. J. H. van Es for statistical assistance and Messrs. J. A. van Dijk and G. A. Bangma for technical assistance.

One of the authors (P. R.) wishes to thank Dr. Tom Walsh, Director, Agriculture Institute, Dublin, for permission and financial assistance to work at Wageningen.

\section{References}

Ash, R. W., 1962. Gastro-intestinal re-entrant cannulae for studies of digestion in sheep. Animal Production, 4 : 309-312.

Bruce, J., Goodall, E. D., Kay, R. N. B., Phillipson, A. T. and Vowles, L. E., 1967. The flow of organic and inorganic materials through the alimentary tract of the sheep. Proceed. of the Royal Soc. of London, $166: 46-63$.

Corbett, J. L., Greenhalgh, J. F. D., Gwynn, P. E. \& Walker, D., 1958. Excretion of chromium sesquioxide and polyethylene-glycol by dairy cows. Britt, J. Nutr. 12: 266-276.

Harris, L. E. \& Phillipson, A. T., 1962. The measurement of the flow of food to the duodenum of sheep. Animal Production, 4 : 97-116.

Harrison, F. A. \& Hill, K. J., 1962. Digestive secretions and the flow of digesta along the duodenum of the sheep. J. Physiol., 162:225-243.

Hogan, J. P. \& Phillipson, A. T., 1960. The rate of flow of digesta and their removal along the digestive tract of the sheep. Britt. J. Nutr., $14: 147-155$.

Hogan, J. P., 1964. The digestion of food by the grazing sheep. 1. The rate of flow of digesta. Austr. J. Agric. Res., 15: 384-396.

Hydén, S., 1955. A turbidimetric method for the determination of higher polyethylene glycols in biological materials. Ann. Roy. Agr. Coll., Sweden, 22: 139.

Sperber, J., Hydén, S. \& Ekman, J., 1953. The use of polyethylene glycol as a reference substance in the study of ruminant digestion. Ann. Roy. Agr. Coll., Sweden, 20: 337.

Phillipson, A. T., 1952. The passage of digesta from the abomasum of sheep. J. Physiol., 116: 84-98.

Phillipson, A. T. \& Ash, R. W., 1965. Physiological mechanisms affecting the flow of digesta in ruminants. In: Physiology of digestion in the ruminant. Butterworth, 1965.

Scheel, K. C., 1936. Colorimetric determination of phosphoric acid in fertilisers with the Pulfrich photometer. Z. Anal. Chem., 105: 256-269.

Singleton, A. G., 1961. The electromagnetic measurement of the flow of digesta through the duodenum of the goat and the sheep. J. Physiol., 155:134-147. 